\title{
Factors Influencing University Staff Health-Promoting Lifestyle Behaviours in Nigeria: A Qualitative Descriptive Study
}

\author{
Elizabeth M. Joseph-Shehu ${ }^{1,2}$ \& Busisiwe P. Ncama ${ }^{1}$ \\ ${ }^{1}$ School of Nursing and Public Health, University of KwaZulu-Natal, College of Health Sciences, Durban, South \\ Africa \\ ${ }^{2}$ Department of Nursing Science, Faculty of Health Sciences, National Open University of Nigeria, Abuja, Nigeria \\ Correspondence: Dr Elizabeth M. Joseph-Shehu, Department of Nursing Science, Faculty of Health Sciences, \\ National Open University of Nigeria, 91 Cadastral Zone, Nnamdi Azikiwe Expressway, Jabi, P.M.B. 581, Gariki, \\ Abuja, Nigeria. E-mail: ejoseph-shehu@noun.edu.ng
}

Received: September 24, 2019 Accepted: October 15, 2019 Online Published: December 5, 2019

doi:10.5539/gjhs.v12n1p46 URL: https://doi.org/10.5539/gjhs.v12n1p46

\begin{abstract}
Introduction: The role of health promoting-lifestyle in the prevention of noncommunicable diseases that is global epidemics cannot be emphasis. This study examined resources available in a university that enhance and maintain health-promoting lifestyle behaviour of staff and explore factors influencing health-promoting lifestyle behaviour of staff.
\end{abstract}

Methods: The study adopted a qualitative descriptive study design. The study setting was a university with multiple satellite campuses and a staff total of 2,657 at the time of data collection. Data were collected from both academic and non-academic staff of the university through in-depth interviews. Data were analysed using content analysis and Nvivo version 11 was used for data management.

Results: Health promotion resources available in the institution were a health facility, a nutritional facility and a physical and fitness facility. The findings revealed that factors influencing health-promoting lifestyle behaviour of staff were lack of institutional health policy and protocol, work overload, lack of planned and consistent health promotion awareness, and economic factors. The majority of our participants did not see health facilities as a means of health promotion; instead they saw it as a resource to be used when they were sick rather than for health promotion services like health screening.

Conclusion: The study concluded that institutional health policy and protocol is key in improving the health of workers. Healthy workers made a healthy institution and for institutional aim to be achieved, workers need to be healthy. Therefore, emphasis should be placed on preventive management than curative management.

Keywords: health-promoting lifestyle behaviours; resources; qualitative design; health promotion activities; university staff

\section{Introduction}

Over three decades ago the World Health Organization (WHO) held its first international conference on health promotion with the goal of achieving health for all by the year 2000 (World Health Organization, 2015). The WHO defined health promotion as a process of enabling people to take responsibility and improve their health, and it goes beyond healthy lifestyle to well-being (World Health Organization, 2015). Despite international and national efforts in advancing health promotion and reducing risks for non-communicable diseases the current statistic showing the burden of non-communicable diseases (NCDs) in both developed and developing countries provide a basis for more actions at all levels. Importantly, health-promoting lifestyle of the individuals is critical to control of NCDs (Tol, Tavassoli, Shariferad, \& Shojaeezadeh, 2013; Majra, 2013; WHO, 2017). The health-promoting lifestyle of an individual entails activities and behaviours that promote quality of life and prevention of diseases (Tol et al., 2013). Health-promoting lifestyle behaviour (HPLB) is described as the individual's beliefs, attitudes, and actions directed at maintaining and promoting his/her health. It encompasses ones' nutritional values, physical activity, interaction with one's environment through interpersonal relations, taking health responsibility, stress management, and self-fulfilment (Sonmezer, Cetinkaya, \& Nacar, 2012; Aqtash \& Van Servellen, 2013; Nacar et al., 2014). Enhancing HPLB is key to prevention and control of NCDs and their associated complications among 
adults (Kirag \& Ocaktan, 2013; Majra, 2013; Cipriano, Neves, Cipriano, Chiappa, \& Borghi-Silva, 2014; Ali, Jaacks, Kowalski, Siegel, \& Ezzati, 2015; WHO, 2017).

Recent studies have shown that factors influencing health-promoting lifestyle of workers include low motivation, low interest in health-promoting programmes, and workers feeling healthy and already adopting a healthy lifestyle. Willingness to change lifestyle and desire to lose weight are identified are other factors influencing workers participation in HPLBs (Lakerveld, IJzelenberg, Van Tulder, Hellemans, Rauwerda, Van Rossum, \& Seidell, 2008; Groeneveld, Proper, van der Beek, Hildebrandt, \& van Mechelen, 2009; Person, Colby, Bulova, \& Eubanks, 2010; Rongen, Robroek, Van Ginkel, Lindeboom, Altink, \& Burdorf, 2014; Bardus, Blake, Lloyd, \& Suzanne Suggs, 2014). Beyond individual worker's health-promoting lifestyle, WHO identified good governance, health illiteracy and healthy cities (World Health Organization, 2015) as three essential components for bringing about healthy individuals who will make up a healthy city and thus healthy workplaces. A healthy workplace is described as 'one in which workers and managers collaborate to use a continual improvement process to protect and promote the health, safety, and well-being of all workers and the sustainability of the workplace' (WHO, 2010).

Despite the WHO emphasis on need for collaboration between workers and managers for sustained health promotion in the workplace, none of the recent studies reported on manager-employee collaboration in planning the health promotion programme or on considering factors that could influence the programme. The WHO identified universities in particular as organizations that should drive health promotion by committing to principles of health for all, targeting staff and students as well as the communities in which they are located (World Health Organization, 2015). The WHO position indicates provision of conceptual and practical guidance to support health-promoting universities, but very few studies reports on health promotion services and facilities in universities that enhance health-promoting lifestyle of staff.

Universities are expected to promote and protect the health of students, staff and their surrounding communities (Tsouros, Dowding, Thompson, Dooris, \& World Health Organization, 1998). The influence of university staff who follow a health-promoting lifestyle will extend to their students, families and the communities to which the staff and students belong. To add enriching data to findings from various quantitative studies and the few qualitative studies that have explored health-promoting lifestyles of workers (Bardus et al., 2014), this study used qualitative study design to explore the resources available in the selected university and the factors that can enhance HPLB of the staff. The findings will be of assistance in planning interventions that will encourage staff to follow an effective and efficient health-promoting lifestyle. The participating university staff included both academic and non-academic workers who spent a significant part of their lives in the institution as would be the case also for other workers. Management staff among the participants were senior members of staff involved in decision-making either at the study centres or headquarters of the institution.

\subsection{Objectives of the Study}

To examine resources available in a university that enhance and maintain health-promoting lifestyle behaviour of staff and to explore factors that influence university staff to adhere to health-promoting lifestyle behaviour.

\section{Methods and Materials}

A qualitative descriptive study was conducted among staff of a university with satellite campuses (referred to as study centres) across the country through in-depth interview. Purposive sampling technique was used to select 24 staff from the university to ensure representation of all staff designations or cadres and theoretical saturation. The sample consists of the principal officers of the institution, management staff at the selected study centre (these two groups are referred to as management staff in this study), representative of academic staff, senior and junior non-academic that have spent more than twelve months in the institution. Characteristics of study participants are presented in Table 1.

The study was approved by the Biomedical Research Ethics Committee of the University of KwaZulu-Natal, Durban, South Africa (BFC423/16) and the National Open University of Nigeria (NOUN) Health Research Ethics Review Committee (NHREC 04). Gatekeeper permission was obtained from the management of university where participants were recruited. The researchers explained the aim of the study and informed consent was obtained in writing from all the participants before data collection

In-depth interviews were conducted with the participants between October 2016 and January 2017 on factors influencing HPLB of staff. The instrument was developed by the authors in accordance with the aim and objectives of the study and revised by two experts in public/community health nursing. We conducted pilot study to assess the appropriateness and applicability of the interview guide, to estimate the time for data collection, to ensure that all the variables in the study is covered and to appraise the feasibility of the study. 
Each interview took place in the participant's office at a scheduled time following written and verbal consent. Most of the interviews were conducted after closing hours to avoid interruption and also to maintain privacy. Every interview was audio-recorded with the consent of the participants; duration of each interview was between 15 and 30 minutes. Recorded interviews were transcribed verbatim and the transcripts were made anonymous to protect the participant's identity. The transcripts were checked against the original recordings from the field for data completion and accuracy before proceeding to analysis.

\subsection{Trustworthiness of the Study}

Credibility: Comprehensive field notes were kept during the data collection process that included a record of gestures and other nonverbal cues by participants. Further documentation to ensure data credibility included a daily register and reports kept at the clinic and gym centre, and an observational checklist accurately recording use of the available resources. Participants were also asked to confirm data obtained in the data collection interviews. We also ensure the principle of theoretical saturation.

Confirmability: Confirmability of data was ensured through verbatim transcription of interview records and data triangulation.

Dependability: The adequacy of the study protocol was assessed by two senior researchers who were not part of the study. A comprehensive description of the study setting, details of the study design and, technique for data analysis are all provided.

Transferability: We provide detailed information for potential transferability, including description of the study, the methodology and the participants.

\subsection{Data Analysis}

Data was analysed using content analysis (Du Plooy-Cilliers, Davis \& Bezuidenhout, 2015), and Nvivo version 11 (QSR International) was used to manage data. Recorded interviews were transcribed verbatim along with an observational checklist and notes taken during the interview sessions. Familiarization with the contents of the audiotape and the transcripts was done by listening and reading repeatedly. Before analysis commenced, identities of participants and places were removed from each transcript. The cleaned data were then uploaded into Nvivo. Data exploration was done using Nvivo queries to familiarize the data and get to know how participants responded to the interview questions. Autocoding was done to reorganize the interview questions for each participant. Themes were developed from the research questions and narratives of study participants. Relevant information was coded clearly and systematically for each participant. Related and similar codes were grouped as themes, subthemes were extracted from the themes, and themes and subthemes were reviewed and refined as analysis progressed. For validation of the results, the researchers met to agree on the themes and subthemes.

\section{Results}

Twenty-four staff members participated in the interviews. Table 1 lists participants' characteristics.

Table 1. Participant characteristics

\begin{tabular}{lllll}
\hline Participant ID & Gender & Years in service & Study location & Designation \\
\hline P1 & Male & $6-10$ years & Headquarters & Management staff \\
P2 & Male & $6-10$ years & Headquarters & Management staff \\
P3 & Male & $6-10$ years & Headquarters & Management staff \\
P4 & Male & $1-5$ years & Headquarters & Management staff \\
P5 & Male & $6-10$ years & Headquarters & Management staff \\
P6 & Female & $6-10$ years & Headquarters & Staff \\
P7 & Male & 11 years and above & Headquarters & Management staff \\
P8 & Male & $6-10$ years & Study centre & Staff \\
P9 & Female & 11 years and above & Study centre & Management staff \\
P10 & Female & $6-10$ years & Study centre & Management staff \\
P11 & Male & $1-5$ years & Study centre & Staff \\
P12 & Female & $6-10$ years & Study centre & Management staff \\
\hline
\end{tabular}




\begin{tabular}{lllll}
\hline P13 & Female & $6-10$ years & Study centre & Staff \\
P14 & Male & $6-10$ years & Study centre & Staff \\
P15 & Male & $6-10$ years & Study centre & Management staff \\
P16 & Male & $6-10$ years & Study centre & Management staff \\
P17 & Male & $6-10$ years & Study centre & Staff \\
P18 & Female & $6-10$ years & Study centre & Staff \\
P19 & Male & 11 years and above & Study centre & Management staff \\
P20 & Female & $6-10$ years & Study centre & Staff \\
P21 & Female & $6-10$ years & Study centre & Staff \\
P22 & Male & $1-5$ years & Study centre & Management staff \\
P23 & Male & $1-5$ years & Headquarters & Staff \\
P24 & Female & $1-5$ years & Headquarters & Staff \\
\hline
\end{tabular}

Twenty-four staff participated in the interview and table 1 shows the characteristics of the participants.

\section{Objective 1: Resources available in the university that support staff health-promoting lifestyle behaviour}

Four themes emerged in relation to health-promotion resources available to support university staff in maintaining a health-promoting lifestyle (see Table 2):

health facilities

nutritional facilities

physical fitness and relaxation facilities

healthy environment

Table 2. Summary of existing university health-promotion resources

\begin{tabular}{|c|c|c|c|c|}
\hline $\mathbf{S} / \mathbf{N}$ & Themes & Frequency & Meaning & Evidence \\
\hline 1 & Health facilities & 23 & $\begin{array}{l}\text { Services and facilities that } \\
\text { promote health } \\
\text { responsibility behaviours }\end{array}$ & $\begin{array}{l}\text { The university has some health facilities like a } \\
\text { laboratory where people check their vital signs and } \\
\text { access first aid treatment at the university } \\
\text { headquarters. The facilities are managed by } \\
\text { nurses... they send health information to people, } \\
\text { especially during the Ebola issue. They circulated } \\
\text { health leaflets to staff members (P1) }\end{array}$ \\
\hline 2 & $\begin{array}{l}\text { Nutritional } \\
\text { facilities }\end{array}$ & 21 & $\begin{array}{l}\text { Services and facilities that } \\
\text { promote good nutritional } \\
\text { practices }\end{array}$ & $\begin{array}{l}\text { We have a restaurant; their food is good... It is } \\
\text { privately owned, and their food is okay }(\mathrm{P} 14)\end{array}$ \\
\hline 3 & $\begin{array}{l}\text { Physical fitness } \\
\text { and relaxation } \\
\text { facilities }\end{array}$ & 19 & $\begin{array}{l}\text { Services and facilities that } \\
\text { promote physical health } \\
\text { and relaxation }\end{array}$ & $\begin{array}{l}\text { There are a gym and club for staff; there are about } \\
\text { three items there like bicycles... They are effective } \\
\text { (P18) }\end{array}$ \\
\hline 4 & $\begin{array}{l}\text { Healthy } \\
\text { environment }\end{array}$ & 7 & $\begin{array}{l}\text { An environment that is } \\
\text { serene and blessed with } \\
\text { natural resources }\end{array}$ & $\begin{array}{l}\text { There is paw-paw, Moringer (we were told that is a } \\
\text { good tree) in the compound. There are fruit and } \\
\text { vegetables in the premises that the staff can use... } \\
\text { Also, people can stay under the tree to receive fresh } \\
\text { air instead of staying under the air condition if one is } \\
\text { not too busy in the office which can also enhance one } \\
\text { health (P13) }\end{array}$ \\
\hline
\end{tabular}

Subthemes emerging from these four themes are indicated in Figure 1. 
Subthemes related to health facilities: sickbay, health services, National Health Insurance Scheme (NHIS). (See Figure 1)

Sickbay: Participants reported that a functioning sickbay was available in two facilities of the university. Some stated that the existing sickbay was just to provide first aid care to staff. Some participants expressed the need to have a health facility at study centres similar to the one at the university healthquarters.

Related interview extracts:

there is sick bay at the headquarters but there is none here to take care of the staff when the need arises. i.e. even if it is just one person to take care of staff, such is highly needed here but we don't have such. sick bay should be made as a precondition for the establishment of any centre (P22).

we have an infrastructure for specialist hospital here, look at it, but they have not started doing anything. No equipment because they are looking for partnership. Our sick-bay there you can only get panadol, or this antimalarial drug and can get the blood pressure checked (P7).

We don't have a Sick bay, we don't have a professional nurse but they just gave us First aid box that have Panadol, cotton wool, bandages, iodine and those little things ( $\mathrm{P} 10)$

About to organize one through memorandum of understanding (MOU) with a private hosp. the hospital can be sending their staff once in a while to check us especially during exams (P20).

The reason be that individually we have hospital that we attend and they are NHIS activated but I think we should have some little health facilities for instance first aid box fully stocked (P16)

Health services: Participants reported that health promotion outreach programmes were occasionally provided by private organizations for some categories of staff by virtue of their position or job responsibility. Reportedly, on one occasion a doctor was invited to give health education to managerial staff which included provision of a sphygmomanometer, and at another time defibrillators were provided at some study centres along with training for a member of staff on how to use it. The defibrillators were still working at the time of data collection. Also, leaders of study centres who have knowledge and interest in health by virtue of their field of study occasionally provide health information to staff and students. In addition, participants stated that sick bay staff provide health education to staff on occasions such as threat of an epidemic. Participants also stated that clinic staff offer individual health education and counselling as the need arises.

Related interview extracts:

in 2014, the then VC organized a doctor from LUTH to educate member of the senate on how to control blood pressure. Books and digital blood pressure apparatus were distributed to us, the senate members (deans of faculty, directors and all professors). In 2016, a member of staff was send for training on the use of defibrillator for students used during examination period because of student's population. They queue for long period in the sun and there has been history of student fainting or collapse during the process (P15).

We have some periodic seminars on health for drivers, but it is outsourced to an organization, for instance it is compulsory for all drivers to have eye test (P5)

we give health education once in a while when there is an epidemic. ... when we do screening is with external body. Sometimes a company came to do visual acuity they suggest further investigation if necessary. At a time, it was cervical screening in 2013. We also give health education on individual basis like nutrition (P24)

National Health Insurance Scheme: Participants indicated that every staff member had access to the National Health Insurance Scheme (NHIS) and that there were health management organizations (HMOs) attached to the institution, although staff used these facilities only when they were sick or had a health complaint.

Related interview extracts:

Yes, we have this health insurance kind of a thing. All of us are attached to any hospital of our choice for one to patronize when one is sick.(P9)

the institution has HMO in which every staff visit whenever they are sick. This HMO does not organize any health promotion programme for us. (P15)

NHIS is the only thing and they organize no any health promotion activities, staff only go there when they are sick. (P21)

Subthemes related to nutritional facilities: restaurant; nutritional education (services and facilities that promote good nutritional practices among staff of the institution). (See Figure 1) 


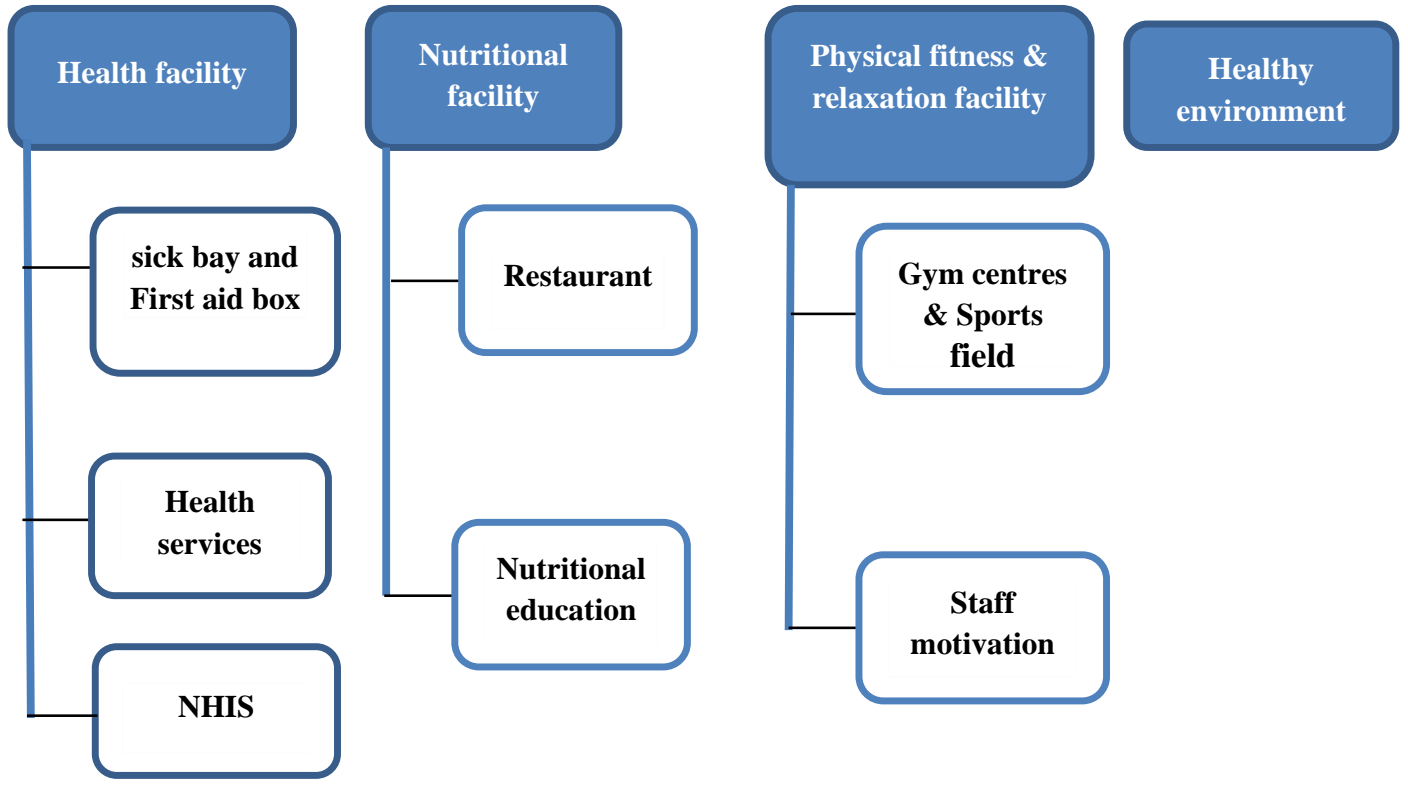

Figure 1 . Themes and subthemes on university staff health promotion resources

Restaurants: Includes all types of venue where staff can eat. Some participants reported availability of restaurants or cafeterias that provided good nutrition for staff in a clean environment. Some reported existence of local eateries within a study centre but not under supervision. One participant reported that management was planning to institute a hygienic staff eatery within the particular centre. Some participants also expressed displeasure about non-availability of any restaurant facility in their study centre or its vicinity, regarding this as detrimental to a health-promoting lifestyle.

Related interview extracts:

Yes, there is a private owned one in the premises. They sell Africa food and their food is okay. The environment is good they also sell fruit and vegetables. (P13)

We are planning for a good restaurant as we have none presently but we have local eatery all over the place. (P4) our staff eat junks as there is no available cafeteria in the compound. If such is at the centre someone will monitored what they cook and the little money will also be enough the eat healthy food but if it outside they can be using ajino-motor [a seasoning many people react negatively to] to cook. (P21)

Nutritional education: One participant who was a nutritionist reported that he gave individual nutritional education when necessary. Some respondents noted that management staff at the study centres who had nutritional knowledge occasionally provided nutritional health education to staff under them. However, there was also strong critique from some participants on the negative health consequences of inadequate nutritional knowledge.

Related interview extracts:

I do give nutritional health related talk as I am a nutritionist. (P15)

tell us what we are supposed to do in the morning, the kind of diet we are supposed to take, what to be taking in the morning. (P6)

I know because of their economic status and responsibilities, they buy soft drink and bread always but if you educate them they can buy bread and moin-moin (beans pudding), beans etc. which is much healthier. (P21)

Subthemes related to physical fitness and relaxation facilities: gym centre; sports field; staff motivation (services and facilities that promote physical health and relaxation). (See Figure 1)

Gym centre and sports field: Participants reported availability of two well-equipped and functioning gym ccntres. They reported that one of the gym centre was located at the staff recreational club relaxation facility. A majority of participants expressed a desire for the institution to provide gym and relaxation facilities in all the study centres as they currently had none. However, some participants reported lack of funds and availability of space as challenges because some centres were not in a permanent site. 
Related interview extracts:

We have a Gym centre, field for sport like in Kaduna. Some centres are in permanent sites and they have enough space for exercise, sport and game for both indoor and outdoor games. (P1)

no gym centre at the study centre but it is good if we have it as it can help us to improve our health and be more productive in the office. (P15)

centres may not possibly have every facility as the headquarters because many centers have limited space and with the open and distance learning $(O D L)$ method such may not really be necessary because it is financially intensive. Also, study centres are just to coordinate, as they are to serve a bridge to the headquarters and student within that immediate environment. (P22)

Staff motivation: Participants noted efforts that management had made to ensure staff were physically fit, including registration of the university as a member of Nigeria University Staff Association Games (NUSAG), providing staff with sports kit and promoting staff who participated and won in the games. Management provision of sports kit was cited as encouraging and helping to improve health-promoting behaviour of staff.

Related interview extracts:

encouragement of the staff to undergo sporting will also help to improve our health standard, and that is why the university now registered to be a member of NUSAG and engage in the games every two years. (P7)

Technically, management is encouraging people to participate in NUSAG and Senate are ready to sponsor people to participate in the exercise. I think such is a way of healthy lifestyle promotion. (P22)

staff were encouraged to participate in games, even people have been promoted for winning medals in staff game. Some have been given cash gifts for doing well in sports and management staff were given canvas and sports outfits to encourage them to practice health-promoting behaviour. (P1)

Healthy environment: Some of the participants reported on their working environment as an element in the resources that can potentially promote healthy lifestyle behaviours. They commented that a conducive environment for good health of staff contributes very significantly to health promotion.

Related interview extracts:

Our environment is serene, no pollution, people breath in clean air which contributes to good health. (P15)

Yes, this environment is less stressful than Lagos and more relax here. The environment is clean and no much noise or any form of pollution in the premises. (P8)

sanitary condition is okay, we try as much as possible to see that the rest room are clean with disinfectant like twice in week. The gardeners take care of the weeds. This compound a times the mosquitoes' way they deal with us here, we have so much insects and all that but most of the time we fumigate and when we do that it helps a lot. Someone that is not aware of all these we be prone to diseases. (P14)

\section{Available resources}

Table 3 shows the available resources in each of the university centres selected for the study, derived from the observational checklist used in collecting data.

Table 3. Resources available in the institution that contribute to staff health promotion

\begin{tabular}{|c|c|c|c|c|c|c|c|}
\hline \multirow{2}{*}{ Resources } & \multicolumn{7}{|c|}{ University campuses } \\
\hline & SL1 & SL2 & SL3 & SL4 & SL5 & SL6 & SL \\
\hline Policy and protocol on staff health promotion & $*$ & $*$ & * & $*$ & $*$ & $*$ & $*$ \\
\hline $\begin{array}{l}\text { Sick bay, three health providers, ambulance } \\
\text { and defibrillator }\end{array}$ & & $*$ & * & $*$ & * & $*$ & * \\
\hline Eateries & & $*$ & $\sqrt{ }$ & $*$ & $\sqrt{ }$ & $*$ & $*$ \\
\hline Medical laboratory & $\boldsymbol{V}$ & $*$ & * & $*$ & * & $*$ & * \\
\hline
\end{tabular}




$\begin{aligned} & \text { Gym centre with instructor } \\ & \text { Sick bay with two health providers and } \\ & \text { defibrillator }\end{aligned}$
Sport field
$\begin{aligned} & \text { Gym and Staff recreational centre } \\ & \text { Defibrillator }\end{aligned}$

Note. $\checkmark=$ available, $*=$ not available, $\mathrm{SL}=$ university campus

\section{Objective 2: Factors influencing university staff health-promoting lifestyle behaviour:}

Four themes emerged in relation to factors influencing health-promoting lifestyle behaviour of university staff (see Table 4):

lack of institutional health policy and protocol

work overload of staff and high level of stress

lack of health promotion awareness

economic factors

Table 4. Factors influencing health-promoting lifestyle behaviour of university staff

\begin{tabular}{|c|c|c|c|c|}
\hline $\mathbf{S} / \mathbf{N}$ & Themes & Frequency & Meaning & Evidence \\
\hline 1 & $\begin{array}{l}\text { Lack of institutional } \\
\text { health policy and } \\
\text { protocol }\end{array}$ & 24 & $\begin{array}{l}\text { Existing institutional } \\
\text { policy and protocol on } \\
\text { staff health promotion }\end{array}$ & None yet but we are thinking about it (P5). \\
\hline 2 & $\begin{array}{l}\text { Work overload of staff } \\
\text { and high level of stress }\end{array}$ & 21 & $\begin{array}{l}\text { Overwhelmed with work, } \\
\text { that is, much work to be } \\
\text { done within a short } \\
\text { period }\end{array}$ & $\begin{array}{l}\text { Because of work, sometimes you bring food but } \\
\text { unable to eat because of workload. Stress is } \\
\text { also high because we have few staff for each } \\
\text { duty and by time you want to eat your food } \\
\text { would have been cold and lost the appetite } \\
\text { (P20). }\end{array}$ \\
\hline 3 & $\begin{array}{l}\text { Lack of health } \\
\text { promotion awareness }\end{array}$ & 17 & $\begin{array}{l}\text { Staff claimed they are not } \\
\text { aware of the importance } \\
\text { of health promotion }\end{array}$ & $\begin{array}{l}\text {... if not that you [investigator] came now we } \\
\text { wouldn't have been aware of all these things } \\
\text { [HP lifestyles and services] (P19). }\end{array}$ \\
\hline 4 & Economic factors & 12 & $\begin{array}{l}\text { Lack of finance to invest } \\
\text { in HP activities }\end{array}$ & $\begin{array}{l}\text { One main challenge to staff health-promoting } \\
\text { behaviours is finance; it is a big challenge to } \\
\text { such because some professionals will need } \\
\text { money before they provide services. Also cost of } \\
\text { eating healthy like the cost of fruits and } \\
\text { vegetables ( } \mathrm{P} 22) \text {. }\end{array}$ \\
\hline
\end{tabular}

Subthemes emerging from these four themes are indicated in Figure 2.

Subtheme related to lack of institutional health policy and protocol: management interest in staff health promotion. (See Figure 2).

Management interest in staff health promotion: All the participants reported that there was no existing policy and protocol on health promotion for staff. A few participants did, however, mention that they were planning to have a health policy for the institution which would enhance staff health promotion. They noted in addition that staff health promotion had never been discussed in any managerial meetings because the focus was always on the 
academic activity of the institution. A majority of participants indicated that they would raise and discuss ways to enhance staff health promotion in their institution. In addition, they indicated awareness of the importance of staff health promotion in attaining the goals of the university. Some participants expressed need for a policy on staff health promotion entailing physical activity and health responsibility at all campuses of the institution.

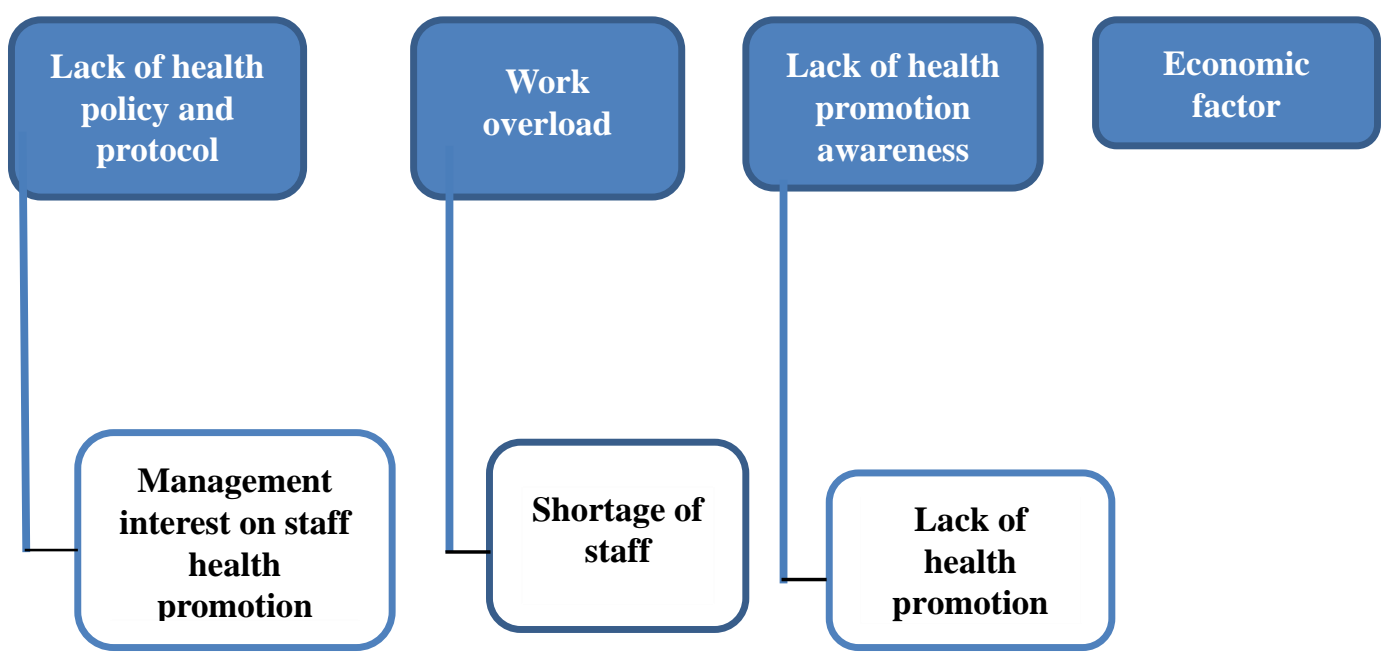

Figure 2. Factors influencing university staff health-promoting lifestyle behaviours

Themes and sub-themes emerged from our study on factors influencing university staff health-promoting lifestyle behaviours are presented in Figure 2.

Related interview extracts:

We don't have protocol or policy that enhance staff health promotion, it is good if we can practice and put it as a policy, every Wednesday when you come with your advocacy dress; we do compulsory health exercise. I think it is worthwhile and necessary for us to have health promotion services. Because not until one slump before we can learn our lesson in a hard way. That time we were given the blood pressure apparatus, it was the time when the VC of a university slumps. (P1)

... has not been discussed before but with this your project, awareness is created, and I hope we would discuss it in our next operational meetings because health promotion of staff is very important as we are faced with too much stress in the study centre. We work round the clock even at home I still work for NOUN because of the nature of the programme. Recently we lost staff in Abuja on her way back home from the office. (P15)

... health promotion lifestyle practice is need and important at this time because we have lost several staff this year. We also lost one professor that his colleagues said he was not sick and no symptoms could result in the sudden death. (P22)

Subtheme related to work overload: shortage of staff. (See Figure 2)

Shortage of staff: Almost all the participants reported on a daily overburden of work that sometimes meant they had no time to eat. Some mentioned that they took opportunity to eat when they were less busy since there was no stipulated break time within the eight-hour working period. In some cases, participants reported that although there was no particular time for a break, staff were not stopped from having a break. Other participants reported that there was a break period within their working hours and that each unit chose a time that suited their work:

Related interview extracts:

...no break time, you eat in your office and eat when you are not busy. We don't have time for lunch because most of the time we are busy and you must not keep the student waiting. Sometimes we take breakfast in the afternoon. (P18)

when you are less busy take your break; nobody will punish you for taking that break. Once you are through you come back. But if you are busy you can shift it to a particular time, that is how we do our break. We don't have specific time for break. (P7) 
due to volume of work we have, we take up 8:00 in the morning and close any time we don't have any specific time because our student will start coming when they close from their offices and you can only close from the office when we have attended to all the students with us. Here, no specific hours for break. (P11)

Subtheme related to health promotion awareness: lack of health promotion services. (See Figure 2)

Lack of planned and consistent health promotion services: A majority of the participants reported that there were no health promotion services in the institution in the form of regular seminars and or workshops targeted at information sharing, skills building or healthy lifestyle. Some participants said that where facilities were available, these were not effectively made use of by staff unless they fell sick and needed to seek medical care. However, participants did indicate staff readiness to participate in health promotion activities if available.

Related interview extracts:

Both males and females use the gym centre but females most, and most of staff come to the centre because their doctors asked them to come for the gym. (P23).

... begin to have health literacy, even those of us that we are elite; we don't even care how we look after our health. That is why some people will go and they will not wake up again; they will say I saw him yesterday, healthy and hearty. How do you know that the person is healthy and hearty... I will advise the university to organize a seminar maybe on zone basis so that staff will benefit. It will go a long way to save our lives. (P10)

Each staff on their own make an effort to live a healthy lifestyle, it will be good if the university can organize training, seminars and workshops on healthy lifestyle organized that involve everybody not selected one. (P18)

Economic factors: This is another theme that emerged from our findings (Table 4). Participants reported lack of finance as a significant factor influencing healthy lifestyle for staff. One participant underlined this issue in pointing to a noticeably increased flow of staff visiting the clinic between the middle and end of every month when they were short of money. Participants expressed concerns about health of staff members possibly related to not eating well and poor health responsibility behaviours. They further reported that giving staff more incentives would be a strong encouragement for maintaining a healthy lifestyle. One participant noted, however, that while provision of free health-promotion services by the university would encourage staff to participate, if these services came with a cost, staff would need to pay personally. Another participant insisted, nonetheless, that money should not be a problem when it comes to health promotion of staff.

Related interview extracts:

averagely, we have 100 staff visiting the clinic weekly from middle to the end of the month and common conditions staff reported were malaria, gastric ulcer, gastrointestinal tract infection like diarrhea. There is also high incidence of old and new hypertension cases. (P24)

I want to say specifically that I am not comfortable because, from the look of things, our staff are not really doing well in that area of feeding. They are always crying of nothing to eat. They come from morning till evening looking for groundnut to just put in their mouth something like that. In that aspect, you can see comfortably well that they are not really eating well. Although, salary is paid regularly but their responsibilities are far more than the salary. (P8)

I wouldn't say finance is a major issue because some of this health something does not involve much money and prevention is better than cure. Health promotion will also make the university have good job output, because young people, strong people will work hard and achieve the objective of the institution, when people are sick they cannot achieve because they are weak and sick. (P1).

\section{Discussion}

Tsouros et al. state that universities can potentially become model health-promoting settings (Tsouros et al., 1998). This paper explores resources in a university environment that enhance staff HPLB and factors that influence staff HPLB. Components of workplace health promotion need to be strategic, integrated and systematic in transformation of the workplace environment through institutional policies to benefit workers' health (Pronk, 2013). Key issues in encouragement of workers' HPLB are building health policy, creating a supportive environment, development of personal skills through health literacy. and reoriented health services(Nöhammer, Schusterschitz \& Stummer, 2013; World Health Organization, 2015). In enhancement of university staff HPLB, four central themes emerge in this study: health facility, nutritional facility, physical fitness and relaxation facility, and healthy environment. Each of these encompassed key elements of health promotion (World Health Organization, 2015). However, in the institution that was the setting of the study, our findings revealed an absence of written policy to provide strategic guidance on resources, facilities and services to drive health-promoting 
lifestyle of staff in many of the study locations. The core consideration in having health-promotion facilities in an institution is to empower the staff to take responsibility for their health through behaviour that helps them to live a healthy and productive life (WHO, 2008; Nacar et al., 2014).

Apart from absence of guiding health policy and protocol, our study further highlighted factors influencing staff health-promoting lifestyle. These include work overload, lack of health promotion awareness and financial constraints of staff members. Pronk reported that workplace factors, socioeconomic status and environmental factors are critical factors that affect HPLB of workers (Pronk, 2013). Overload in the work environment of the study institution increases the vulnerability of staff to stress-induced health challenges. Participants in this study noted that if facilities like health-promoting lifestyle programmes were available to every staff member it would enhance health-promoting lifestyle; instead they just strive to maintain a healthy lifestyle on their own. Worker health can be seen as a product of individual behaviour and work environment, therefore managements striving to achieve set goals need to strengthen personal health practices and resources by providing health-specific programmes and services (Ljungblad, Granström, Dellve \& Åkerlind, 2014), and do so consistently so that they become part of the institutional culture.

Again, while work overload and financial constraints were identified as barriers to HPLB management, staff and administrators stated that no amount of money invested in health of workers could be too much. Health promotion enhances job productivity, reduces absenteeism due to ill health, and reduces hospitalization and hospital cost (Wierenga, Engbers, Van Empelen, Duijts, Hildebrandt \& Van Mechelen, 2013; Rongen, Robroek, van Lenthe \& Burdorf, 2013). These observations give credence to the need for a re-orientation of institutional leadership so that there is due recognition of the synergy between the health and well-being of staff and so that health-promoting practices such as insisting on regular health breaks for workers during work periods are prioritized and institutionalized. Establishing a health policy that makes staff health promotion a priority was accordingly suggested as a way to encourage staff participation in health promotion programmes. Management support for HPLB of staff is best shown by creating an enabling environment for health promotion activities as an integral part of organizational strategy (Milner et al., 2013). The concept of HPLB seems still to be new despite the role it plays in the prevention and control of NCDs (Tol et al., 2013; Joseph-Shehu \& Ncama, 2017; WHO, 2017). Most of our participants regarded health facilities such as the NHIS as synonymous with 'sickness': resources to be used when you are ill or have a health complaint. It did not occur to them that such facilities could be a channel of health promotion, nor did they make use of the NHIS for health promotion services such as health screening. Mandatory health screening for workers could be systematically built into the health culture of universities. In general, to achieve a successful population HPLB, government, institutions and health professionals need a change in emphasis and practice, since the focus in many health care systems still tends to be on curative management rather than preventive measures (Johansson, Stenlund, Lundström \& Weinehall, 2010; World Health Organization, 2015).

This study reopens the general discourse of health-promoting universities in the context of increasing NCD prevalence worldwide and in Nigeria, in view of the critical role that universities play as change organizations. The strength of this study lies in its focus on exploring. through in-depth interviews. the resources and factors in the university environment that influence staff HPLB. The data was generated from staff at a range of performance levels, thereby providing insight into the predisposition of managerial and operational staff and highlighting what needs to be given attention for future interventions. The study was conducted in a single university with multiple campuses across Nigeria, and findings would be relevant to other universities in the country with similar structure.

There is limited literature to support findings of this study, and data having been collected from a multi-campus university could restrict generalization of the findings to single-campus universities. However, the study context of a university setting in Nigeria with multiple campuses is highly representative in terms of taking participants across the states, exploring all resources that can enhance staff HPLB, and corroborating information from staff with observation of what was on ground and what the factors were that influence staff HPLB. For fuller understanding and documentation of the level of readiness of universities in Nigeria to be health-promoting, further research is needed in other universities under federal, state and private administration in the country that are not open and distance learning institutions.

Healthy workers made a healthy institution and for institutional aim to be achieved, workers need to be healthy. The role of health promoting-lifestyle in the prevention of noncommunicable diseases that is global epidemics cannot be emphasis. For university to be a health promotion university there are minimum essential resources that are required of them which include availability of health policy and protocol that involves planed and consistent health promotion activities. This paper gives an account of resources in a university environment that enhance staff 
HPLB and factors that influence staff HPLB. Four resources are identified for improving university staff HPLB: health facility, nutritional facility, physical fitness and relaxation facility, and healthy environment. Key factors identified as barriers to university staff HPLB are lack of health policy and protocol, and low awareness in regard to health-promotion activities. This study provides guidance for effective and efficient health-promotion interventions for university staff and offers a basis for investigating current practice in other universities, and in Nigeria in particular. The study recommends that to achieve a successful population health-promoting lifestyle behaviour that can maintain health and prevent diseases, government, institutions and health professionals need a change in emphasis and practice as many health care systems still focus more on curative management than on preventive measures.

\section{Declarations}

\section{Ethics approval and consent to participate}

Ethical approval was obtained from the National Open University of Nigeria (NOUN) Health Research Ethics Review Committee (NHREC 04) and Biomedical Research Ethics Committee (BREC) and the University of KwaZulu-Natal, Durban, South Africa (BFC423/16). Written and verbal consent was also obtained from each respondent prior to data collection.

\section{Consent for publication}

Participants' consent to publish the findings was obtained along with the informed consent. All personal data will be removed and no identifying data will be published.

\section{Availability of data and material}

All data generated or analysed during this study are included in this manuscript [and its supplementary information files].

\section{Competing Interest}

The authors declare that they have no competing interests.

\section{Funding}

There was no specific funding received for this study.

\section{Author Contribution}

Study design: Elizabeth Joseph-Shehu, and Professor BP Ncama (supervisor); Data collection, analysis and original draft preparation: EMJ; Funding acquisition: EMJ, BPN Supervision, review and editing: BPN. All the authors approved the final draft.

\section{Acknowledgements}

The authors wish to express their appreciation to the National Open University of Nigeria and to the University of KwaZulu-Natal College of Health Science for their contributions to this study. Our appreciation also goes to the participants for their time and cooperation during the study.

\section{Competing Interests Statement}

The authors declare that there are no competing or potential conflicts of interest.

\section{References}

Ali, M. K., Jaacks, L. M., Kowalski, A. J., Siegel, K. R., \& Ezzati, M. (2015). Noncommunicable diseases: three decades of global data show a mixture of increases and decreases in mortality rates. Health Affairs, 34(9), 1444-1455. https://doi.org/10.1377/hlthaff.2015.0570

Aqtash, S., \& Van Servellen, G. (2013). Determinants of health-promoting lifestyle behaviors among arab immigrants from the region of the levant. Research in Nursing \& Health, 36(5), 466-477. https://doi.org/10.1002/nur.21555

Bardus, M., Blake, H., Lloyd, S., \& Suzanne Suggs, L. (2014). Reasons for participating and not participating in a e-health workplace physical activity intervention: A qualitative analysis. International Journal of Workplace Health Management, 7(4), 229-246. https://doi.org/10.1108/IJWHM-11-2013-0040

Cipriano, G., Neves, L. M. T., Cipriano, G. F. B., Chiappa, G. R., \& Borghi-Silva, A. (2014). Cardiovascular disease prevention and implications for worksite health promotion programs in Brazil. Progress in cardiovascular diseases, 56(5), 493-500. https://doi.org/10.1016/j.pcad.2013.10.018 
Du Plooy-Cilliers, F., Davis, C., \& Bezuidenhout, R. (2015). Research matters. Cape Town, South Africa: Juta and Company Ltd.

Groeneveld, I. F., Proper, K. I., van der Beek, A. J., Hildebrandt, V. H., \& van Mechelen, W. (2009). Factors associated with non-participation and drop-out in a lifestyle intervention for workers with an elevated risk of cardiovascular disease. International Journal of Behavioral Nutrition and Physical Activity, 6(1), 80. https://doi.org/10.1186/1479-5868-6-80

Johansson, H., Stenlund, H., Lundström, L. \& Weinehall, L. (2010). Reorientation to more health promotion in health services-a study of barriers and possibilities from the perspective of health professionals. Journal of multidisciplinary healthcare, 3, 213. https://doi.org/10.2147/JMDH.S14900

Joseph-Shehu, E. M., \& Ncama, B. P. (2017). Evidence on health-promoting lifestyle practices and information and communication technologies: scoping review protocol. BMJ open, 7(3), e014358. https://doi.org/10.1136/bmjopen-2016-014358

Kirag, N., \& Ocaktan, E. M. (2013). Analysis of health promoting lifestyle behaviors and associated factors among nurses at a university hospital in Turkey. Saudi medical journal, 34(10), 1062-1067.

Lakerveld, J., IJzelenberg, W., Van Tulder, M. W., Hellemans, I. M., Rauwerda, J. A., Van Rossum, A. C., \& Seidell, J. C. (2008). Motives for (not) participating in a lifestyle intervention trial. BMC Medical Research Methodology, 8(1), 17. https://doi.org/10.1186/1471-2288-8-17

Ljungblad, C., Granström, F., Dellve, L., \& Åkerlind, I. (2014). Workplace health promotion and working conditions as determinants of employee health. International Journal of Workplace Health Management, 7(2), 89-104. https://doi.org/10.1108/IJWHM-02-2013-0003

Majra, J. (2013). Do our medical colleges inculcate health-promoting lifestyle among medical students: A pilot study from two medical colleges from Southern India. International Journal of Preventive Medicine, 4(4), 425 .

Milner, K., Greyling, M., Goetzel, R., Da Silva, R., Kolbe-Alexander, T., Patel, D., . . Beckowski, M. (2013). The relationship between leadership support, workplace health promotion and employee wellbeing in South Africa. Health promotion international, 30(3), 514-522. https://doi.org/10.1093/heapro/dat064

Nacar, M., Baykan, Z., Cetinkaya, F., Arslantas, D., Ozer, A., Coskun, O., . . Yilmazel, G. (2014). Health promoting lifestyle behaviour in medical students: a multicentre study from Turkey. Asian Pac J Cancer Prev, 15(20), 8969-8974. https://doi.org/10.7314/APJCP.2014.15.20.8969

Nöhammer, E., Schusterschitz, C., \& Stummer, H. (2013). Employee perceived effects of workplace health promotion. International Journal of Workplace Health Management, 6(1), 38-53. https://doi.org/10.1108/17538351311312312

Person, A. L., Colby, S. E., Bulova, J. A., \& Eubanks, J. W. (2010). Barriers to participation in a worksite wellness program. Nutrition research and practice, 4(2), 149-154. https://doi.org/10.4162/nrp.2010.4.2.149

Pronk, N. P. (2013). Integrated worker health protection and promotion programs: overview and perspectives on health and economic outcomes. Journal of occupational and environmental medicine/American College of Occupational and Environmental Medicine, 55(12 0), S30. https://doi.org/10.1097/JOM.0000000000000031

Rongen, A., Robroek, S. J. W., van Lenthe, F. J., \& Burdorf, A. (2013). Workplace Health Promotion. American journal of preventive medicine, 44(4), 406-415. https://doi.org/10.1016/j.amepre.2012.12.007

Rongen, A., Robroek, S. J., Van Ginkel, W., Lindeboom, D., Altink, B., \& Burdorf, A. (2014). Barriers and facilitators for participation in health promotion programs among employees: a six-month follow-up study. BMC Public Health, 14(1), 573. https://doi.org/10.1186/1471-2458-14-573

Sonmezer, H., Cetinkaya, F., \& Nacar, M. (2012). Healthy life-style promoting behaviour in Turkish women aged 18-64. Asian Pac J Cancer Prev, 13(4), 1241-1245. https://doi.org/10.7314/APJCP.2012.13.4.1241

Tol, A., Tavassoli, E., Shariferad, G. R., \& Shojaeezadeh, D. (2013). Health-promoting lifestyle and quality of life among undergraduate students at school of health, Isfahan university of medical sciences. Journal of education and health promotion, 2, 11. https://doi.org/10.4103/2277-9531.108006

Tsouros, A., Dowding, G., Thompson, J., Dooris, M., \& World Health Organization. (1998). Health Promoting Universities: Concept, experience and framework for action.

Wierenga, D., Engbers, L. H., Van Empelen, P., Duijts, S., Hildebrandt, V. H., \& Van Mechelen, W. (2013). What is 
actually measured in process evaluations for worksite health promotion programs: a systematic review. $B M C$ Public Health, 13(1), 1190. https://doi.org/10.1186/1471-2458-13-1190

World Health Organization [WHO]. (2008). Workplace health promotion. Retrieved from http://www.who.int/occupational_health/topics/workplace/en/print.html

World Health Organization [WHO]. (2010). Healthy workplaces: A model for action For employers, workers policy-makers and practitioners.

Retrieved

from http://apps.who.int/iris/bitstream/handle/10665/44307/9789241599313_eng.pdf;jsessionid=CF08B29C438 A94014AA4D7BC4936338E?sequence $=1$

World Health Organization [WHO]. (2015). The Ottawa Charter for Health Promotion. Retrieved November, 2015, from http://www.who.int/healthpromotion/conferences/previous/ottawa/en/

World Health Organization [WHO]. (2017). Noncommunicable diseases. Retrieved from http://www.who.int/mediacentre/factsheets/fs355/en/

\section{Copyrights}

Copyright for this article is retained by the author(s), with first publication rights granted to the journal.

This is an open-access article distributed under the terms and conditions of the Creative Commons Attribution license (http://creativecommons.org/licenses/by/4.0/). 